\title{
Contratos, Novas Tecnologias e Produtividade do Trabalho entre os Avicultores do Sul do Brasil *
}

\author{
Armando Dalla Costa
}

Departamento de Economia-Universidade Federal do Paraná

\section{Resumo}

A avicultura brasileira apresentou nas últimas quatro décadas um conjunto de modificações ligadas à estrutura organizacional que englobam grande parte dos processos produtivos, administrativos e de organização do trabalho. A industrialização do setor teve início na década de 1960, impulsionada pelas empresas estabelecidas no Sul do Brasil, sobretudo a Sadia, Perdigão, Ceval, Frangosul, Aurora, entre outras. A produção passou de 217 mil toneladas em 1970 para 9,2 milhões de toneladas em 2006. Nesse mesmo período, o consumo interno brasileiro passou de 2,3 quilos para 36 quilos por habitante/ano e o preço do quilo de carne no varejo caiu de US\$ 4,05 para menos de 1 dólar. Apesar desse forte aumento no consumo do mercado interno, a produção cresceu a ponto de tornar o Brasil o maior exportador mundial de frangos e derivados. Este artigo tem por objetivo analisar a influência dos contratos com os agricultores produtores de frango e as novas tecnologias empregadas nos aviários, ao longo desse tempo, e que tipo de transformações causaram na organização e na dinâmica do trabalho desses agricultores, chamados integrados. Para tanto

\footnotetext{
* O autor agradece os comentários e sugestões dos pareceristas anônimos da revista. Possíveis erros e incorreções desta versão final são de responsabilidade exclusiva do autor.
} 
procedeu-se a uma revisão na literatura e um levantamento junto aos produtores rurais e aos técnicos das empresas que lhes prestam assessoria, para identificar tais transformações. Concluiu-se que os contratos são um elemento-chave na relação com os integrados e que a produtividade no trabalho avançou em função das novas tecnologias e do saber acumulado pelos agricultores.

Palavras-Chave | Contratos; Avicultura; Integrados; Tecnologia; Produtividade do Trabalho

Códigos JEL | L11; L23; L25

\section{Abstract}

Poultry production in Brazil went through significant changes in the last four decades, which embraced large part of the productive, administrative and labor organization processes. The industrialization of the sector began in the 1960s and 1970s, led by firms from the South of Brazil, including Sadia, Perdigão, Ceval, Frangosul and Aurora, among others. Production rose from 217.000 tons to 9.2 millions tons in this period. In the same period poultry consumption increased from 2.3 to $36 \mathrm{~kg}$ per capita per year, while the price of poultry fell from US\$ 4.05 per $\mathrm{kg}$ to less than 1 dollar. In spite of the increase in domestic consumption, the increase in production was so remarkable that Brazil became the largest exporter of poultry meet in the world. This paper discusses technological change in the sector and how it affected the production process by producers contractually linked to the big industrializing firms, which are called integrados. To do so, this paper uses many literature references and also collects information from many poultry producers and firms' employees in order to identify such transformations in the production processes. It is concluded that labor productivity was heightened by the new technologies and the knowledge accumulated by producers.

Keywords | Poultry; Integrated Producers; Technology; Productivity of Labor

\section{JEL-Codes $\quad$ L11; L23; L25}




\section{Introdução}

A avicultura brasileira, a do Sul do país em particular, foi um dos setores da economia contemporânea que passou por profundas transformações. A atividade deixou de ser tradicional e artesanal - galinhas caipiras criadas no terreiro - para se tornar um dos setores de ponta em tecnologia e produção, tanto no abastecimento do mercado interno como nas exportações. Em 1970, após cerca de uma década de produção industrializada, o volume chegou a 217 mil toneladas, o consumo por habitante/ano a 2,3 quilos, enquanto o preço médio do quilo no varejo estava em US\$ 4,05 (Dalla Costa, 2000:1). Em 2006 a produção passou para 9,28 milhões de toneladas, o consumo por habitante chegou a 36 quilos e o preço médio do quilo da carne manteve-se abaixo de 1 dólar.

Não foi apenas no mercado interno que a atividade ganhou importância. As empresas brasileiras começaram a exportar frango e derivados em 1975, vendendo, no primeiro ano, 4 mil toneladas a um valor de US\$ 3,3 milhões. As exportações continuaram crescendo, para chegar em 2006, num volume de 2,5 milhões de toneladas, a um valor de US \$ 3,2 bilhões, transformando o Brasil no maior exportador mundial. ${ }^{1}$

Neste texto o objetivo é entender a importância dos contratos com os produtores integrados ${ }^{2}$ e analisar as transformações na tecnologia e na produtividade do trabalho desses produtores. Para isso procedeu-se a uma revisão da literatura sobre a avicultura brasileira, assim como a respeito da nova economia institucional que trata das relações contratuais entre empresas e fornecedores. Em seguida buscou-se compreender a atuação das agroindústrias no sentido de implantar uma parceria via contratos de integração. A seqüência do texto analisa as evoluções na tecnologia interna

\footnotetext{
1 Talamini, Dirceu J.D.; Martins, Franco M.; Novaes, Marcos, "A resposta da avicultura ao desafio da gripe aviária", in Anuário 2007 da Avicultura Industrial, São Paulo: Gessulli, ano 98, n.11, ed.1.151, p.18-26, 2006.

2 "O sistema de produção integrada é um mecanismo através do qual uma propriedade rural, geralmente agricultura familiar, cria os animais (ou outros produtos, como fumo e leite) destinados ao abate e industrialização em associação com uma agroindústria. O agricultor, criador de frangos, perus, codornas [...] é responsável pela construção e equipamento do aviário, mão-de-obra e a gestão dos demais meios de produção como eletricidade, água, gás, cama do aviário e o cuidado com as aves. A agroindústria, por sua vez, faz a entrega dos pintos de um dia, garante assistência técnica e veterinária, medicamentos, ração e transporte. A função do integrado é criar as aves, sob orientação da agroindústria e vendê-las exclusivamente à mesma, que as abate, industrializa e vende" (Dalla Costa, 1993, p.154).
} 
dos aviários, assim como o tempo necessário para os avicultores criarem os frangos até o ponto do abate. No final, são apresentadas as principais conclusões.

\section{Contratos como instrumento de relações empresariais: elementos da teoria dos custos de transação}

Como o objetivo não é aprofundar a teoria, assinalaram-se apenas aspectos que contribuem para uma análise da avicultura, levando em conta os contratos de parceria avícola realizados entre as agroindústrias e os avicultores integrados, seus fornecedores de matéria-prima.

A Teoria dos Custos de Transação - TCT é a principal vertente da Nova Economia Institucional - NEI. De acordo com Williamson (1975), os pontos que caracterizam a NEI são um contexto evolutivo e uma renovada atenção para a questão das transações. Sendo a segunda sua principal vertente, de outra forma a mais importante característica da NEI está relacionada à transação como foco de análise. Para Simon (1991) o objetivo da NEI é apresentar uma formulação explicativa dos fenômenos econômicos a partir do estabelecimento do contrato entre os agentes. Uma característica dessa corrente é que ela manteve no centro da teoria o mercado e a troca.

Essa abordagem contratual está relacionada com a TCT que foi desenvolvida, a partir da década de 1970, por Oliver Williamson e pode ser considerada a linha básica de trabalhos da NEI (Pessali, 1998). O objeto de análise de Williamson é a transação e ele defende que qualquer relação contratual, formal ou informal é passível de ser analisada pela TCT. Os atores dessa economia podem ser denominados individuos contratuais (contractual men). $\mathrm{O}$ indivíduo contratual é potencialmente oportunista, age sob racionalidade limitada, executa transações econômicas que envolvem características relativas à especificidade do ativo, incerteza e freqüência das transações. Tais contratos são regidos sob formas alternativas de governança que visam restringir o oportunismo, atribuindo e reforçando direitos de propriedade e ajuste a eventos não antecipados. $\mathrm{O}$ indivíduo contratual é guiado pela competição e fará as suas decisões de make-or-buy em favor do menor custo da estrutura de governança (Williamson, 1975; Pessali, 2006). 
De acordo com essa teoria, as transaçōes podem ser caracterizadas segundo o grau de especificidade dos ativos. Um ativo específico é aquele que possui características que o singularizam ou o tornam membro de um seleto grupo. As transações que envolvem ativos específicos também são conhecidas como transações em pequeno número (small numbers). Nesse tipo de transação, somente um pequeno número de agentes está capacitado a participar. A especificidade dos ativos reduz tanto os contratantes quanto os contratados interessados em estabelecer um contrato.

Segundo Williamson (1991), para a TCT a principal característica de uma transação deve ser expressa na especificidade do ativo a ela relacionado:

a) especificidade geográfica ou locacional, em que a proximidade entre estágios sucessivos da transação é importante (proporcionando economias em estoque, transporte, conservação, controle da poluição ou outras);

b) especificidade física do ativo, como em moldes ou materiais especiais, máquinas de único uso etc.;

c) especificidade do capital humano, obtida através do learning by doing;

d) ativos dedicados, feitos sob encomenda ou para atender exclusivamente um certo cliente;

e) ativos de qualidade superior ou relacionados a padrões ou marcas;

f) especificidade temporal, em que o tempo envolvido no desenrolar da transação pode implicar perda de valores transacionados, como no caso de produtos perecíveis.

O grau de especificidade está associado à necessidade de maiores salvaguardas contratuais e a um maior interesse em estender a duração do contrato. Pode-se utilizar a idéia de gastos irrecuperáveis (sunk costs) para um ativo em que a quebra do contrato implica a exposição à perda total (ou residual, se o contrato tiver sido cumprido parcialmente) de seu valor produtivo, ou a usos alternativos de baixo retorno. Já ativos pouco ou nada específicos não incorrem em tais perigos, encontrando usos alternativos de mesmo retorno ou clientela discreta, já que devemos estar lidando com um bem ou serviço de características padronizadas e utilização geral.

Williamson (1985) argumenta que, na presença de especificidade dos ativos, uma transação inicialmente feita por um processo de licitação ou com 
muitos ofertantes pode ter esse processo de contratação discreta fortemente atingido em sua eventual renovação. Isso porque o primeiro ganhador, ao longo do contrato, cria vantagens de custos e/ou conhecimentos técnicos ou administrativos que se farão presentes nas licitações futuras e pesarão a seu favor.

De acordo com Azevedo (1997), a especificidade do ativo é apenas uma das dimensões das transações, sendo a freqüência com as transações a outra de suas características. A importância da repetição manifesta-se em dois aspectos, a diluição dos custos de adoção de um mecanismo complexo por várias transaçôes e a possibilidade de construção de reputação por parte dos agentes envolvidos na transação. A repetição de uma transação possibilita também que as partes adquiram conhecimento umas das outras (o que reduz a incerteza); que se construa uma reputação em torno de uma marca (o que cria um ativo específico); e, ainda mais importante, que se crie, em alguns casos, um compromisso confiável (credible commitment) entre as partes em torno do objetivo comum de continuidade na relação. Esse aprendizado corresponde a uma redução da incerteza.

Outro aspecto das transações é a estrutura de governança que as rege. Para Williamson (1998), as transações com diferentes atributos estão alinhadas com estruturas de governança, que se distinguem nos seus custos e competências. De acordo com a TCT, a transação é a unidade básica de análise e a governança é o meio pelo qual a ordenação é efetuada. Segundo Williamson (1995), a estrutura de governança é modelada para impedir a conduta oportunista por alguma das partes envolvidas na transação. O mesmo autor, em publicação anterior (1985), assume que alguns indivíduos podem ser oportunistas parte do tempo e que a qualidade de ser merecedor de confiança raramente é visível ex ante. Como conseqüência, são feitos esforços de sinalização ex ante e são criadas salvaguardas ex post.

Williamson (1985) sugere três tipos básicos de estruturas de governança:

1) governança pelo mercado - forma adotada em transações não-específicas, especialmente eficaz no caso de transações recorrentes. Não há esforço para sustentar a relação e, na avaliação de uma transação, as partes precisam consultar apenas sua própria experiência; 
2) governança trilateral - é exigida a especificação ex ante de uma terceira parte tanto na avaliação da execução da transação, quanto na solução de eventuais litígios. É mais adequada para transações ocasionais, sejam elas de caráter misto ou específico;

3) governança específica de transação - nesse caso, o fato de os ativos transacionados não envolverem padronização aumenta o risco da transação e a possibilidade do surgimento de conflitos de solução custosa e incerta.

\section{Mudanças na produção avícola do Sul do Brasil}

A avicultura no Sul do país passou por profundas transformações a partir de 1961, quando empresas do agronegócio da região diversificaram suas atividades, entrando nesse setor de produção com a intenção de modernizálo. Num primeiro momento optaram pela integração vertical para cobrir "falhas de mercado", uma vez que outras empresas não tinham tecnologia nem interesse em produzir pintos de 1 dia e rações para atender à pequena demanda desse novo setor. $\mathrm{O}$ mesmo ocorreu em outras etapas da produção, como no caso da comercialização, que levou os grupos empresariais a criarem suas próprias empresas de transporte terrestre e aéreo, ${ }^{3}$ os matrizeiros e incubatórios, o abate das aves nos assim chamados "frigoríficos", a produção de industrializados (produtos com maior valor agregado, do tipo nuggets), o transporte e a comercialização (Quadro 1). Nesse caso percebe-se a especificidade dos ativos, exigindo que os empresários construíssem uma estrutura de governança vertical completa, pois essas dificuldades não poderiam ser sanadas apenas via contratos, o que se tornou viável posteriormente, com o avanço da produção.

Uma vez implantada, a integração vertical favoreceu o crescimento dos volumes produzidos, permitindo assim alcançar as vantagens da economia de escala. Essa vantagem competitiva, aliada às condições de produção mais favoráveis no Sul, permitiu que as empresas dessa região suplantassem as de São Paulo, Rio de Janeiro e Minas Gerais, historicamente as maiores

\footnotetext{
3 A Sadia criou a Sadia S.A. Transportes Aéreos, que funcionou como empresa de transporte de cargas entre 1956 e 1962. Em seguida foi transformada na Transbrasil, que chegou a ser a terceira maior empresa de aviação comercial brasileira. A Perdigão também manteve empresa aérea para transporte de produtos perecíveis, ao mesmo tempo em que era dona de uma frota de caminhões próprios, até meados de 1960.
} 
produtoras do país. Em 1975, com o início das exportações, o modelo de produção do Sul mostrou-se mais competitivo para atender esse novo mercado e as empresas dessa região passaram a atender também a demanda externa.

O Quadro 1 ajuda a compreender as diversas etapas da produção na avicultura integrada do Sul do país, desde sua implantação até meados dos anos 1990 .

$\mathrm{Na}$ medida em que outros concorrentes “independentes" se estabeleceram na região, algumas etapas do processo foram terceirizadas, como o transporte e a criação de pintos de 1 dia, que levou à terceirização também dos matrizeiros e incubatórios. Com isso, as agroindústrias concentraram suas atividades no seu foco de ação, mantendo etapas estratégicas, tais como as fábricas de rações, os abatedouros, a industrialização dos subprodutos de carne e a comercialização. Há duas exceções na integração vertical nunca assumidas pelas agroindústrias, que são o desenvolvimento genético (exige altos investimentos e muita tecnologia, feito por multinacionais) e a criação e engorda dos frangos (altos investimentos, muita mão-de-obra e agrega pouco valor, feita pelos integrados), conforme análise a seguir.

\section{Os agricultores integrados às agroindústrias}

Uma das etapas fundamentais para o funcionamento da avicultura industrial é o fornecimento da matéria-prima de maneira constante e com a qualidade exigida pelo mercado interno e externo. No Sul do Brasil para produtos como leite, fumo, frangos, suínos etc., estabeleceu-se uma prática de parceria entre as empresas compradoras e os integrados.

Para conhecer a relação entre as agroindústrias e os produtores, é necessário estudar como a Sadia e outras empresas que seguiram seu exemplo fizeram para garantir sua matéria-prima. A Sadia implantou um sistema de assistência aos integrados ainda no começo dos anos 1950, na tentativa de melhorar o fornecimento de suínos, para o único abatedor que mantinha à época, em Concórdia, sua cidade de origem. ${ }^{4}$

4 Para compreender a história da Sadia, ver, entre outros, Dalla Costa (1993, 2000), Fontana (1980), Teixeira (1994), Silva (1991), Mior (1992), Campos (1987). 
Contratos, Novas Tecnologias e Produtividade do Trabalho entre os Avicultores do Sul do Brasil

\section{QUADRO 1}

Etapas da produção e comercialização, com sua forma de gerenciamento no sistema de integração vertical da avicultura brasileira - 1995

\section{Etapas da produção}

Pesquisa genética

"avós"

Matrizeiros

Incubatórios

(produção de pintos

de 1 dia)

Produção de ração

Vacinas e remédios

Criação e "engorda" das aves

Abate das aves

Cortes e

industrialização

Transporte

Comercialização

Mercado

\section{Formas de gerenciamento}

Importação (sobretudo da América do Norte e Europa) - adquirida fora da integração vertical.

Empresa - importando os ovos, as empresas produzem suas próprias matrizes. Primeira etapa do processo de integração vertical dos principais grupos nacionais.

Empresa - integração vertical nas principais empresas (compra eventual de terceiros para complementar a produção própria). Compra de terceiros, por parte de muitas empresas de médio e pequeno porte, sobretudo em São Paulo e Minas Gerais.

Empresa - integração vertical. As grandes empresas produzem toda a ração utilizada por seus integrados (vendem eventualmente para terceiros). Em São Paulo existem empresas que atuam fora do sistema de integração, especializadas em produção de rações e vendem para os "avicultores independentes" e de "fundo de quintal".

Adquiridos pelas empresas fora do sistema de integração vertical. Os pintos de 1 dia já saem vacinados dos incubatórios para os aviários. Os remédios posteriores são comprados pelas empresas e repassados aos integrados.

Agricultor - integração vertical, com serviço terceirizado, desde o início da avicultura industrial no Sul do país e realizado por pequenos agricultores integrados. Em São Paulo e outros estados, essa etapa da produção era realizada por grandes produtores independentes. A expansão das empresas do Sul fez com que parte da produção fosse feita também por pequenos agricultores integrados.

Empresa - integração vertical, sendo realizado nos próprios estabelecimentos da empresa. O abatedouro é colocado como ponto "central" da cadeia produtiva. É a partir dele que se organiza a integração vertical, tanto "para trás" como "para frente".

Empresa - integração vertical. Os cortes são geralmente feitos em salas anexas aos próprios abatedouros. Os produtos industrializados a partir da carne de frango geralmente são elaborados em indústrias próprias para isso, anexas aos abatedouros.

Terceirizado - no início todo transporte era feito pelas empresas. Em 1995, com exceção de alguns serviços especializados, tudo estava terceirizado, desde o transporte de pintos de 1 dia, ração, carregamento dos frangos até o abatedouro e deste às filiais comerciais, até a distribuição aos pontos de venda.

Empresa e terceiros - integração vertical. As principais empresas trabalham com filiais comerciais nos estados onde o consumo é mais importante (Sul, Sudeste e Centro-Oeste). No Norte e Nordeste seus produtos são distribuídos por representantes exclusivos, com exceção da Sadia, que mantém filiais comerciais também nessas regiões.

O principal mercado é o interno. A partir de 1975, as empresas iniciaram as exportações de frango inteiro e, desde 1984, exportam também partes de frangos. Até 1995, no entanto, as vendas externas representaram cerca de $13 \%$ da produção nacional.

Fonte: Dalla Costa, 2000, p.338. 
$\mathrm{Na}$ década de 1950, sob orientação de Victor Fontana (sobrinho de Attilio Fontana, fundador da empresa) e com apoio da Associação Rural de Concórdia, fundada em 1951, iniciou um trabalho para melhorar a qualidade dos suínos. O desafio consistia em romper o modelo tradicional do "porco do tipo banha”, muito bom para produção de gordura animal, ${ }^{5}$ mas não para a industrialização de carne.

"A simples introdução de animais das raças Duroc e Landrace e as melhorias na criação, em meados dos anos 1950, fizeram com que o tempo necessário para os suinos atingirem 100 quilos diminuisse de 14 para 8 meses (de 420 para 240 dias!), com menos banha, mais carne e de melhor qualidade." (Dalla Costa, 2000:206)

Em 1961, quando a Sadia diversificou suas atividades entrando no abate avícola, já dispunha de uma estrutura de técnicos especializados em assistência aos suinocultores. Para não fazer a criação e engorda dos frangos por conta própria, a empresa estabeleceu contratos de parceria com pequenos produtores para essa atividade, sistema que ficou conhecido como "avicultura integrada".

"A avicultura integrada tinha a vantagem de ser um sistema de concepção muito simples. A empresa comprometia-se a fornecer os pintinhos, a ração e todo o suporte técnico necessário. O criador, por sua vez, assumia o compromisso da construção dos aviários, do alojamento e cuidado das aves, seguindo à risca a orientação recebida, até a devolução dos animais à Sadia. Nesse momento seria feito o acerto de contas entre as partes, por critérios previamente estabelecidos de desempenho e eficiência. Tiradas as dúvidas e feitos os ajustes normais a uma nova experiência, alguns colonos aceitaram o programa, assumiram a parceria e ainda nesse mesmo ano de 1961 contribuiram para elevar o total anual de abates da empresa para mais de 90.000 aves." (Teixeira, 1994:46)

\footnotetext{
5 A banha consistia a principal mercadoria do frigorífico da Sadia em Concórdia até o início dos anos 1970, quando esse produto foi substituído, na mesa dos brasileiros, pelo óleo vegetal, sobretudo proveniente da soja.
} 
Para dar conta da assistência a esses produtores, o Departamento de Fomento da Sadia ficou encarregado da coordenação técnico-econômica da criação de suínos e aves. Para desempenhar as novas funções e atender a um número crescente de integrados, a Sadia montou uma estrutura com equipamentos e empregados especializados. No início tratava-se de um pequeno grupo de técnicos que resolvia todo tipo de problemas. Em seguida a empresa contratou uma equipe que se ocupava desde a importação das avós, cuidava das matrizes e prestava assistência técnica.

"Com um grupo de 87 técnicos, dentre os quais 14 veterinários, 11 agrônomos, 55 técnicos agrícolas, 3 zootecnistas, 2 engenheiros florestais e 2 empregados administrativos, o Fomento Sadia continuava fiel aos objetivos definidos em sua criação, 20 anos antes, que eram de gerar e transferir tecnologia aos integrados que se dedicavam à criação de suinos, aves e à agricultura de subsistência como ao reflorestamento." 6

Para formalizar e legalizar a relação entre os integrados e as agroindústrias, foram implantados pelas empresas do Sul do país, Sadia, Perdigão, Ceval, Chapecó, Aurora, Frangosul, Avipal etc., os chamados contratos avícolas, conforme análise a seguir, que permitiram eliminar os atravessadores presentes nos estados de São Paulo e Minas Gerais, onde havia mais produtores independentes, tanto de suínos como de aves. Os produtores daqueles estados eram levados a adquirir dos atravessadores os frangos de 1 dia, a ração e os medicamentos. Eles também se encarregavam do transporte e depois compravam a produção, ganhando em todas as fases do processo. O lucro dos antigos atravessadores ficou com as empresas integradoras, que internalizaram os processos, uma das características da teoria dos custos de transação.

$\mathrm{Na}$ medida em que essas firmas foram expandindo sua atuação geográfica $^{7}$ para outras regiōes, levaram junto o mesmo modelo de produção

6 Sadia Concórdia S.A., Relatório anual, 1977.

7 A Sadia chegou ao final dos anos 1990 com um parque fabril formado por 12 fábricas: em Concórdia e Chapecó (SC), Três Passos (RS), Dois Vizinhos, Francisco Beltrão, Toledo, Paranaguá e Ponta Grossa (PR), Várzea Grande (MT), São Paulo (SP), Duque de Caxias (RJ), Uberlândia (MG). No final de 2004, adquiriu a Só Frangos Produtos Alimentícios, no Distrito Federal. Com a aquisição, a Sadia passou a contar com 13 unidades industriais no Brasil (<http://www.sadia. com.br/br/empresa/historico_2000.asp>. Acesso em 23 de fevereiro de 2007). As unidades industriais da Perdigão são 9 e estão localizadas em Santa Catarina: Capinzal, Videira, Herval d'Oeste, Lages e Salto Veloso; no Rio Grande do Sul: Marau e Serafina Corrêa; no Paraná: Carambeí; em Goiás: Rio Verde (Perdigão, Relatório anual, p.8, 2003). 
e de relação com os fornecedores da matéria-prima, configurando assim na avicultura industrial o que a nova economia institucional e os custos de transação previam (Williamson, 1991).

\section{Contratos de parceria avícola com os integrados}

No começo do processo de integração com os pequenos agricultores, de 1961 até início da década de 1970, quando a produção ainda não atingia grandes quantidades, as firmas não se preocupavam com a efetivação dos contratos e muitas não tinham nem a preocupação de efetivar a relação contratual. Segundo pesquisa realizada em Santa Catarina em 1978, 38\% dos contratos eram escritos, $37 \%$, verbais e $23 \%$, por cadastro. Entre as nove empresas pesquisadas, três utilizavam contratos escritos, duas usavam contratos verbais e cadastro; duas, só contrato verbal e apenas duas celebravam só contratos escritos (CEAG, 1978:143).

Após a efetivação legal dos contratos, continuou valendo mais a confiança entre as partes como pode verificar-se nas palavras de um dirigente da Sadia:

"No início esses contratos eram verbais. O que interessava mais era o perfil do produtor. Estabelecia-se uma relação de confiança mútua entre a empresa e o integrado. Atualmente os contratos são escritos, mas imagino que a maioria dos avicultores nem sequer leu os contratos. Nós praticamente nunca recorremos a eles para resolver nenhum tipo de problema. Eles existem mais por uma exigência legal." ${ }^{8}$

Analisando tais contratos, algumas cláusulas chamam a atenção:

a) fornecimento exclusivo por parte do contratante, dos meios básicos de produção (aves de 1 dia, rações, medicamentos, que permanecem como propriedade da firma);

b) estabelecimento do prazo de entrega de um novo lote de pintos (perus) após a retirada das aves para o abate;

8 Entrevista com o gerente do setor agropecuário da Sadia Concórdia S.A., Concórdia (SC), 18 de abril de 1995 (apud Dalla Costa, 2000, p.200). 
c) obediência rigorosa às normas técnicas estabelecidas pela empresa e prestadas pelo Departamento de Fomento;

d) formas de comercialização e determinação do preço do produto final e direito exclusivo de compra por parte da empresa integradora;

e) fixação da percentagem de quilos de aves vivas que caberá a cada uma das partes, conforme tabela anexa ao contrato;

f) despesas com serviços de tratamento, aquecimento e cuidados com as aves correm por conta do produtor;

g) financiamento dos instrumentos e/ou meios de produção, adiantamento de rações, medicamentos, pintos;

h) permissão à parceira proprietária de acompanhar a criação e engorda das aves;

i) definição dos padrões de qualidade do produto final;

j) tempo de duração do contrato e foro onde se decidem as disputas que porventura possam ocorrer.

Com base na discussão da TCT, essa relação pode ser classificada como uma estrutura de governança verticalizada completa, em que apenas o contratante tem autonomia, não restando nenhum tipo de autonomia ao contratado. A única decisão que este pode tomar, após o término do contrato, é a de não mais renová-lo.

$\mathrm{Na}$ prática, embora haja formulações diversas entre os contratos de integração das diferentes empresas, todos indicam na mesma direção: “[...] do conjunto das cláusulas e procedimentos básicos, a maioria está na dependência direta do poder do integrador e sobre os quais o produtor integrado não tem qualquer controle" (Dalla Costa, 1993:147).

Os "contratos de parceria avícola” têm características próprias, diferenciando-se dos contratos "clássicos" normalmente usados pelas firmas como forma de reduzir custos, garantir o fornecimento das matérias-primas e diminuir os custos de produção. $\mathrm{Na}$ avicultura, trata-se de uma produção específica, de origem animal, que fornece os abatedouros. É uma produção confinada, que exige mão-de-obra especializada, adoção constante de novas tecnologias, tanto em equipamentos como no manejo dos frangos e no seu carregamento, em que o avicultor atinge uma economia de escala devido às 
quantidades de carnes produzidas. Para atender todos esses requisitos e garantir a quantidade de matéria-prima exigida pelas firmas é que se estabelecem os contratos com os integrados.

Existem diversos estudos que buscam esclarecer as vantagens dos contratos para as empresas e os produtores integrados. Entre outros, destaca-se o do Banco de Desenvolvimento Econômico do Estado de São Paulo - BADESP (1987, apud Lopes, 1992:20), para o qual as principais razões pelas quais as empresas estabelecem contratos com os produtores são:

a) necessidade das firmas processadoras oferecerem produtos em quantidade e qualidade exigidos pela demanda. Esta sem dúvida parece ser a grande responsável pelo dinamismo do setor avícola;

b) redução de custo, mediante o suprimento para manter economias de escala;

c) conquista de posição de mercado, mantendo fornecedores fixos que garantem o suprimento de matéria-prima;

d) maior facilidade de aumentar a produção e introduzir tecnologias;

e) necessidade por parte do agricultor e oportunidade de produzir para um mercado assegurado.

A pesquisa realizada pelo Centro de Assistência Gerencial de Santa Catarina - CEAG, em 1978, aponta as vantagens do sistema de integração para as empresas, que são as seguintes: matéria-prima (frango) de maior qualidade de rendimento industrial; abastecimento constante da matéria-prima; redução dos custos industriais nas operações de abate e elaboração da matéria prima; padronização das carcaças; redução de espaços, tempo e capital de giro necessário para estocagem da matéria-prima no período anterior ao abate (CEAG, 1978:80-86).

As principais vantagens dos produtores com esse sistema de integração podem ser resumidas nos seguintes itens: assistência técnica intensa e permanentemente atualizada; utilização de equipamentos e insumos de qualidade, inclusive rações de alto valor nutricional a preços acessíveis; maior produtividade; redução dos custos de produção e maior rentabilidade; melhor preço médio de venda; melhor aproveitamento dos recursos disponíveis na proprie- 
dade (terra, capital e trabalho); dimensionamentos adequados das instalações, com elevação de renda líquida anual e capacitação profissional do produtor (CEAG, 1978:22-25).

Sendo um dos objetivos do texto verificar como evoluíram tanto as tecnologias como a produtividade do trabalho, em seguida serão apresentadas as principais evoluções sofridas pelas tecnologias empregadas e, na seqüência, sua relação com a produtividade do trabalho dos integrados.

\section{As novas tecnologias e sua influência sobre a força de trabalho dos integrados}

A passagem da avicultura caipira ou tradicional para a produção moderna foi lenta e exigiu um longo aprendizado, tanto por parte das agroindústrias como dos produtores da matéria-prima. As empresas não tinham estrutura nem equipamentos adequados para uma produção em larga escala e os agricultores estavam acostumados a criar galinhas caipiras no terreiro, também não adequados para atender uma demanda desse novo tipo.

Foi necessário introduzir mudanças que permitissem uma evolução nos aviários, nos instrumentos de trabalho, na ração, na assistência técnica, na variedade das aves, assim como uma evolução na mentalidade e na maneira como os integrados iriam ocupar-se da criação dos frangos, perus, patos, codornas etc. Para compreender o significado dessas transformações, basta ouvir os próprios produtores ao afirmarem que, com o passar do tempo, "os aviários passaram a ter condições de construção, higiene e controle de temperatura muito melhores que as casas dos próprios integrados" (Entrevista 1,2007$)$.

Se as galinhas caipiras dos terreiros demoravam cerca de seis meses para chegar ao peso de 1 quilo, agora um frango criado no sistema integrado consegue chegar ao mesmo peso em menos de um mês, como pode observar-se pela Tabela 1. 
TABELA 1

Evolução do processo de produção do setor avícola brasileiro, segundo tempo para abate, taxa de conversão e peso da ave: 1970-2006

\begin{tabular}{cccc}
\hline Anos & $\begin{array}{c}\text { Peso } \\
\text { (em kg) }\end{array}$ & $\begin{array}{c}\text { Taxa de conversão } \\
\text { (kg ração/kg carne) }\end{array}$ & $\begin{array}{c}\text { Idade de abate } \\
\text { (em dias) }\end{array}$ \\
1930 & 1,50 & 3,50 & 105 \\
1950 & 1,80 & 2,50 & 70 \\
1970 & 1,70 & 2,00 & 49 \\
1989 & 1,94 & 1,96 & 41 \\
2001 & 2,24 & 1,78 & 39 \\
\hline 2006 & 2,27 & 1,73 & 45 \\
\hline
\end{tabular}

Fonte: CONAB, DIGEM, GEAME apud IPARDES, 2002; Schmidt, Figueiredo e Ledur, 2006, e dados de pesquisa de campo. Nota: organizada e adaptada pelo autor.

Como pode verificar-se na tabela, tanto o ganho de peso como a taxa de conversão e a idade do abate evoluíram lentamente. Foi necessária uma preparação da Sadia e Perdigão, assim como das demais que seguiram seu exemplo. Na Sadia, o impulso para a avicultura industrial foi dado por um de seus funcionários, Ivo Reich, que viajou para os Estados Unidos em 1961. Os primeiros criadores e os abates iniciais estavam longe da produção atual, mas significaram o começo de uma transformação que levou o Brasil a se tornar o maior exportador mundial de carne de aves e derivados.

"Recém chegado de viagem dos EUA, Ivo Reich começou a implantar em Concórdia o modelo norte-americano de 'avicultura integrada'. Conseguiu achar, a uns oito quilômetros da cidade, um colono disposto a realizar a experiência. Diomédio Bósio construiu um pequeno galinheiro de $3 \times 3$ metros, de chão batido, coberto de sapé e aquecido a lenha. Ivo levou para lá 100 pintinhos, que passaram a ser tratados e alimentados com ração especial. Nas primeiras semanas Ivo percorreu a pé muitas vezes o caminho 
para acompanhar o desenvolvimento da criação. Em 85 dias, tempo recorde para a época, Diomédio Bósio já estava trazendo os frangos de volta no seu jipe para o abate na Sadia. Não demorou muito e outros colonos seguiram o seu exemplo." (Teixeira, 1994:47)

É dessa forma que o historiador da empresa descreve a primeira experiência da Sadia com produção integrada de frangos de corte. Vendo o resultado do trabalho, outros colonos seguiram o exemplo e, ainda no ano de 1961, a empresa abateu mais de 90 mil aves.

A experiência da segunda maior empresa do setor é muito parecida. "Em 1960 o abate de frangos na Perdigão se resumia ao trabalho de duas mulheres que, artesanal e manualmente, processavam cerca de 120 aves por semana" (Tassara \& Scapin, 1996:65). No mesmo ano a empresa enviou um técnico para os EUA, onde participou de um curso de especialização em avicultura. Fruto dos avanços introduzidos a partir dessa viagem, teve início, em 1962, o abate de cerca de 500 frangos por dia. As aves abatidas eram resfriadas, transportadas e comercializadas em São Paulo. Em pouco mais de cinco anos, a empresa, que comprou uma pequena máquina depenadeira semi-automática, atingiu a meta de 1.500 frangos abatidos por dia. ${ }^{9}$

A internalização das atividades pelas agroindústrias via integração vertical foi um dos fatores que permitiu o avanço da produção no Sul do país. $\mathrm{Na}$ medida em que a produção cresceu e a demanda exigia maiores volumes, os custos de transação via contratos com os integrados e internalizando várias etapas da produção conseguiu fazer valer, para as empresas integradoras, as vantagens da TCT.

No que se refere às mudanças do setor de produção da matéria-prima, houve evolução no tipo de aviário assim como nos instrumentos de produção internos. As primeiras construções seguiram mais ou menos a lógica dos galinheiros caipiras, feitos com madeiras rudes e sem nenhuma tecnologia, como no caso do primeiro produtor da Sadia. Aos poucos, os galinheiros foram 
substituídos por modernos aviários ${ }^{10}$ com tamanho-padrão de 100 metros de comprimento por 12 metros de largura, com capacidade de produção de 15 mil a 22 mil frangos, dependendo do nível de automação.

Quanto à tecnologia empregada dentro dos aviários, pode-se distinguir quatro fases principais. No início, a partir da avicultura industrial que começou em 1961, o tratamento dos frangos era feito manualmente, a partir de comedouros rudimentares abastecidos a mão pelos integrados, e a água também era fornecida manualmente em bebedouros rústicos. $\mathrm{O}$ aquecimento era feito a lenha, como descrito no exemplo de Diomédio Bósio. Em termos de carga horária em cada aviário, "o trabalho exigia cerca de 7 horas por dia de uma pessoa da família” (Entrevista 2, 2007).

A segunda fase começou no final dos anos 1970 e caracterizou-se pela primeira tentativa de modernização dos instrumentos. Uma correia foi instalada no chão dos aviários, para transportar a ração automaticamente, e a água era fornecida pelo sistema anterior. É verdade que houve diminuição do tempo necessário para fornecimento da ração, pois antes o integrado precisava carregá-la num carrinho de mão por 100 metros de distância, passando entre os frangos sem fazer movimentos bruscos para não assustá-los, mas o sistema tinha diversos inconvenientes.

"Primeiro quanto à homogeneidade da distribuição. Os frangos que comiam a ração, logo no início do processo, engordavam mais rápido, pois comiam os ingredientes dela, enquanto os do final do aviário ficavam praticamente só com a quirera, criando lotes de frangos díspares. Outro inconveniente era que a correia matava muitos frangos, principalmente quando menores, ao prender a cabeça deles nos anéis da correia. Por fim, ao ser ligado o motor da correia, o barulho espantava os frangos, criando um 'estresse' que prejudicava o bom desenvolvimento das aves." (Entrevista 2, 2007)

\footnotetext{
10 "Hoje em dia o custo de construção para um aviário-padrão é de cerca de R\$144 mil. Esse aviário-padrão conta com bebedouros do tipo Nippel, comedouros automáticos e nebulizador (equipamento que espalha uma 'neblina' no aviário, durante o verão, para controlar a temperatura). Por questões de segurança devido à gripe aviária, é cercado por tela, tem um escritório para o técnico, arco de desinfecção na entrada (dois postes com equipamentos para desinfetar todos os caminhões que chegam), casa de compostagem (local onde são enterrados os frangos que morrem) e computador que controla a temperatura, os comedouros automáticos, os exaustores e o nebulizador."(Entrevista 1, 2007)
} 
Para evitar esses problemas, foi desenvolvido um comedouro tubular, abastecido manualmente. Esse novo sistema resolveu o problema da distribuição homogênea e da morte dos frangos, mas tinha outros inconvenientes.

"Os comedouros eram colocados no chão e os frangos sujavam a ração, ao 'ciscar' na cama do aviário. Segundo, se não houvesse um bom controle no abastecimento, podia faltar ração, o que prejudicava os frangos próximos a esses comedouros, pois eram obrigados a parar de se alimentar, atrasando o processo de crescimento." (Entrevista 1, 2007)

Associado ao comedouro tubular foi desenvolvido um bebedouro tubular, mais adequado que o anterior. No entanto,

"ainda não havia resolvido o problema da sujeira e do aquecimento da água no verão, que acabava prejudicando o bom desenvolvimento das aves e exigia uma carga horária intensa, uma vez que os comedouros deviam ser lavados todos os dias, assim como a água precisava ser trocada. Muitas vezes molhavam a cama dos aviários, vazando água pela regulagem da bóia." (Entrevista 1 e 2, 2007)

Para abastecer os comedouros de ração, lavar os bebedouros, retirar os frangos mortos e remover a cama molhada e mexer a cama do aviário, ${ }^{11} \mathrm{o}$ integrado trabalhava entre quatro e cinco horas por dia.

$\mathrm{O}$ avanço mais recente, e aqui se chega à quarta mudança, implementada a partir do início dos anos 1990, foi a introdução combinada de duas técnicas precedentes no caso da ração. Permaneceram os comedouros tubulares, com a distribuição automática da ração sendo feita diretamente dentro de cada um dos comedouros. Com isso,

"acabou o problema do desperdício de ração, da sujeira desta e de sua falta, uma vez que, ao chegar num determinado momento do consumo, a falta

\footnotetext{
11 "Cama do aviário" é uma espécie de revestimento feito com serragem, maravalha ou outra matéria-prima agrícola que permite aos frangos descansarem sem se machucar e que absorve o esterco das aves. No final de quatro ou cinco lotes, essa cama é retirada e serve de adubo para as lavouras de grãos.
} 
de peso liga o automático que mantém sempre os comedouros cheios. Outra vantagem é que a distribuição da ração é feita de maneira homogênea, de tal forma que não há disparidade no crescimento do lote." (Entrevista 2, 2007)

Quanto aos bebedouros tubulares, foram substituídos por um sistema automático, conhecido como bebedouros do tipo Nippel. Nesse caso a água é servida aos frangos através de canos que passam pelo interior de todo o aviário. Cada cano tem pequenos "bicos" embaixo, de tal forma que, ao serem "bicados" pelas aves, soltam água. Dessa maneira a água não precisa ser servida pelo integrado, não suja, não molha a cama do aviário e não falta nunca.

Nessa última combinação de tecnologia, "o integrado gasta cerca de meia hora por dia para tomar conta do aviário, pois suas tarefas se resumem a retirar os frangos mortos, controlar a temperatura e abrir e fechar as cortinas, quando necessário" (Entrevistas 1 e 2, 2007).

Assim como houve combinação entre as vantagens da integração vertical com as estruturas de governança introduzidas via nova economia institucional e via custos de transação, as mudanças ocorridas internamente nos aviários contribuíram para a melhoria do sistema integrado como um todo, melhorando sua eficiência.

Aliadas às novas tecnologias acima mencionadas estão outras novidades desenvolvidas a partir do início dos anos 1990. Destacam-se, nesse caso, os nebulizadores, combinados com grandes exaustores no final do aviário, que ajudam a circular o ar e manter a temperatura adequada. No frio (os invernos no Sul do país são rigorosos) há uma combinação de aquecimento a lenha, para ficar mais barato, ou a gás, que dá menos trabalho, combinado com o fechamento de cortinas, tanto laterais como de teto, para manter a temperatura. Em aviários completamente automáticos, todos esses procedimentos são controlados por computador, diminuindo ainda mais o tempo de trabalho necessário na criação das aves. Apesar desses avanços e dos recursos empregados, a produção no Brasil tem um custo menor, se comparada com os mesmos aviários na Europa e nos EUA, que são completamente climatizados na maior parte do ano.

O problema desse procedimento e desses avanços tecnológicos é um custo cada vez maior na construção, manutenção e modernização dos aviários, 
que poderia inviabilizar a produção caso as agroindústrias fossem obrigadas a esses investimentos. Aqui entra em ação a parte da teoria dos custos de transação, sobretudo o papel dos contratos. As firmas garantem que compram a produção e os produtores assumem o investimento, os cuidados com os animais e garantem a matéria-prima.

Uma das queixas dos integrados é o custo financeiro do investimento, como pode verificar-se pelos dados do oeste do Paraná, no município de Toledo, responsável pelo maior complexo agroindustrial da América Latina no setor de carne de aves e suínos. Segundo Bernartt (2007), os integrados estão enfrentando dificuldades porque, "[...] num país em que a inflação fica em torno de $4 \%$ ao ano, pagar juros que não baixam de $8,75 \%$ ao ano, torna qualquer investimento inviável”. O autor chega a essa conclusão ao analisar os custos do investimento na atividade.

\section{Custo de produção de um aviário-padrão}

\section{Características do aviário}

- 100 metros de comprimento $x 12$ metros de largura $=1.200 \mathrm{~m}^{2}$;

- capacidade para 15 mil aves alojadas;

- número de lotes por ano = 6 (45 a 49 dias por lote);

- pagamento de $\mathrm{R} \$ 0,33$ centavos por ave entregue [média regional em Toledo (PR)].

Cálculo do retorno do investimento

- custo do aviário = R \$ 130 mil (automatizado e climatizado);

- financiamento pelo BNDES (em oito anos, com um ano de carência, a uma taxa de juros de $8,75 \%$ ao ano).

Resultado para o avicultor

- receita líquida do avicultor em oito anos $=\mathrm{R} \$ 135.024,00$;

- valor financiado $=\mathrm{R} \$ 130 \mathrm{mil}+$ juros em oito anos $=\mathrm{R} \$ 50.372,52$;

- deficit de $\mathrm{R} \$-45.348,52$. 
Conclusão: segundo Bernartt (2007), fica comprovado que, com uma remuneração média de $\mathrm{R} \$ 0,33$ centavos, o avicultor, além de não quitar seu investimento em oito anos, ficará devendo $\mathrm{R} \$ 45.348,52$ ao banco. Caso o produtor tenha em mãos os recursos próprios para a aquisição de um aviário no valor de R\$ 130 mil, se ele aplicar o valor em qualquer aplicação financeira, terá um retorno anual maior que os 9,32\% do aviário e ainda não correrá riscos, tais como a influenza aviária, vendavais e outras catástrofes da natureza.

"A situação se agrava se incluirmos o pró-labore do integrado no cálculo, pois só estamos contabilizando o salário do empregado. Se contabilizarmos um pró-labore para o integrado igual ao do funcionário, no valor de $R \$ 4.824,00$ anuais ( $R \$ 402,00$ por mês, sem férias e 13). o custo por ave ficaria em torno de 0,46 centavos, o que tornaria ainda mais inviável o investimento",

afirma Bernartt (2007). O autor conclui que,

“[...] enquanto o consumidor paga em média entre $R \$ 2,50$ e $R \$ 3,00$ o quilo de frango nos mercados, o produtor recebe 0,15 centavos o quilo, com o qual precisa pagar todos os custos ocorridos na produção, tais como: investimento, funcionários, energia elétrica, maravalha, lenha, gás, manutenção de instalaçôes e equipamentos, seguro e outros custos eventuais",

comentando que uma das alternativas seria um aumento no prazo do investimento de 8 para 12 anos e, ao mesmo tempo, uma redução significativa na taxa de juros.

\section{Conclusão}

Como se observou, as transformações na avicultura do Sul do país foram estruturais e trouxeram resultados surpreendentes para o aumento do consumo no mercado interno e para as exportações. No que se refere à criação das aves, as mudanças ocorreram tanto na tecnologia como na organização do trabalho. Os integrados acumularam um conhecimento nesse período que contribuiu para esse aumento na produção, no consumo e nas exportações. 
Uma das maneiras encontradas pelas agroindústrias para viabilizar essa produção foi a estrutura que se criou em torno do processo produtivo e as relações entre os integrados e as agroindústrias, que favoreceram um intenso processo de inovação no setor. Williamson (1994:23) afirma que

"a principal função do contrato jurídico é de fornecer um quadro para a quase totalidade dos tipos de organização coletiva e para a quase totalidade dos tipos de relaçôes, passageiras ou permanentes, entre os individuos e os grupos [...]. Quadro este que não indica quase nunca com precisão as reais relaçôes, mas que indica, grosso modo, ao redor do que se estabelecem essas relaçôes, servindo como um guia ocasional em caso de dúvidas e de referência última, quando a relação deixa de existir".

Como foi visto no texto, é dessa forma que os dirigentes das empresas avícolas entendem o contrato, sendo utilizado como referência jurídica e podendo servir, em último caso, numa eventual disputa jurídica entre os contratantes, mas sendo deixado de lado na maioria das vezes em que se torna necessário resolver os problemas práticos.

Outra conclusão a destacar em relação aos contratos escritos e assinados entre as agroindústrias e os pequenos agricultores é que não sofreram praticamente nenhuma alteração desde quando foram implantados em 1984. Pelos dados da CEAG (1978), em Santa Catarina de 1978, onde iniciou o processo de industrialização do setor, $38 \%$ dos contratos eram escritos, $37 \%$ verbais e $23 \%$ via cadastro. A partir de 1984 eles passaram a ser escritos, no entanto o que mais conta é a relação de confiança entre as empresas integradoras e os produtores integrados. Desde a primeira versão desses contratos ${ }^{12}$ até 2007 , não houve praticamente nenhuma mudança neles.

É verdade que a remuneração dos integrados é questionada por seus representantes, como se verificou no texto. No entanto, a produtividade do trabalho entre eles aumentou sensivelmente desde 1961, quando começaram os abates industriais. Considerando que cada aviário pode produzir, em média, 6 lotes por ano, multiplicando os 15 mil frangos (média por lote), temos um 
total de 90 mil aves/ano. Ao multiplicar por 2,25 quilos (peso médio por ave), temos uma produção de 202.500 quilos de carne por ano, contando com apenas cerca de meia hora por dia de trabalho. Se o total for dividido pelos dias do ano, teremos uma produção de 554,8 quilos de carne por dia (mais de meia tonelada!). Dificilmente outra atividade, num exíguo espaço físico de $1.200 \mathrm{~m}^{2}$ e exigindo apenas meia hora por dia de dedicação, poderia ter uma produção e renda maior que a avicultura. Foi graças aos avanços tecnológicos, combinados com um conhecimento acumulado pelos agricultores integrados, que se pôde chegar a essa altíssima produtividade do trabalho.

Outra conseqüência desse aumento da produtividade no trabalho é o consumo interno. De 1970 para 2006, os brasileiros que comiam 2,3 quilos em média passaram a consumir 36 quilos de carne. $\mathrm{O}$ preço médio passou de US\$ 4,05 para menos de 1 dólar no período recente. Boa parte da elevação da produtividade e do acesso ao consumo pela maioria da população deve-se à elevação da produtividade no processo todo da avicultura, no qual desempenhou papel importante o contrato feito entre as agroindústrias e os integrados.

Destaque-se a contribuição dos avicultores para a manutenção do baixo preço no mercado interno e da competitividade do Brasil no cenário internacional. Em geral produzem-se seis lotes de frango por ano em cada aviário. Para cada lote os integrados recebem, em média, cerca de R \$ 4 mil. Esse montante de recursos é empregado para pagar o financiamento do aviário no sistema financeiro, a depreciação do aviário e de seus equipamentos (a modernização deles, com a introdução de novos equipamentos), assim como a mão-de-obra do produtor. Para remunerar sua mão-de-obra, "sobram cerca de R\$ 500,00 por mês" (Entrevista 1), montante que equivale aos cálculos de Bernartt (2007), que chegou a um valor de R \$ 402,00 por mês. Portanto, pode-se concluir dizendo que, mesmo produzindo mais de meia tonelada de carne por dia, o integrado recebe entre $\mathrm{R} \$ 16,00 /$ dia e $\mathrm{R} \$ 13,40 /$ dia, contribuindo, assim, para o baixo preço do produto no mercado interno e para a competitividade internacional das empresas do setor. 


\section{Referências bibliográficas}

Andreas, A. "A nova Sadia. Com a reestruturação, o frango cede espaço aos congelados e o lucro quadruplica", revista América Latina, p.24-26, 23 de setembro de 1999.

Associação Brasileira de Exportadores de Frangos. <http://www.abef.com.br>, várias consultas.

Associação Gaúcha de Avicultura. <http://www.asgav.com.br>, várias consultas.

Associação Paulista de Avicultura. <http://www.apa.com.br>, várias consultas.

Azevedo, P. "A nova economia institucional", in Farina, E. et al. (orgs.), Competitividade: mercado, estado e organizações, São Paulo: Singular, 1997.

Bernartt, L.A. [presidente da Comissão Técnica de Avicultura do Sindicato Rural Patronal de Toledo (PR)]. "Avicultores pedem socorro". Disponível em <http:// www.portaldoagronegocio.com.br/index.php?p=texto\&\&idT=914>. Acesso em 18 de setembro de 2007.

Campos, I. "Os colonos do rio Uruguai. Relações entre pequena produção e agroindústria no oeste catarinense", Dissertação de Mestrado, Campina Grande, UFPB, 1987.

CEAG - Centro de Assistência Gerencial de Santa Catarina. Análise do sistema de integração agroindustrial em suinos e aves em Santa Catarina, Florianópolis: CEAG, 1978.

Dalla Costa, A. "A Sadia e a produção integrada. O lugar do agricultor no complexo agroindustrial", Dissertação de Mestrado em História, Curitiba, Faculdade de Filosofia, Letras e Ciências Humanas, Universidade Federal do Paraná, 1993.

. "A Sadia e o pioneirismo industrial na agroindústria brasileira", revista História Econômica \& História de Empresas, Associação Brasileira de Pesquisadores em História Econômica, São Paulo: HUCITEC, ano 1, n. 1, p.109-144, fev., 1999.

- L'agroindustrie brésilienne contemporaine: innovations organizationnelles et transformations technologiques dans l'aviculture, Villeneuve d'Asq: Presses Universitaires du Septentrion, 2000. 
Dalla Costa, A. "Sadia, Perdigão e Hermes Macedo: nascimento, expansão e crise por ocasião da passagem do poder nas empresas familiares", in Kirschner, A.M.; Gomes, E.R.; Cappellin, P. (orgs.), Empresa, empresários e globalização, Rio de Janeiro: Relume Dumará, p.153-170, 2002.

Entrevista 1. Entrevista concedida ao autor por um produtor integrado da Sadia, desde o início da década de 1980, Francisco Beltrão (PR), 22 de fevereiro de 2007.

Entrevista 2. Entrevista concedida ao autor por um técnico que trabalha na EPAGRI Empresa de Pesquisa Agropecuária e Extensão Rural de Santa Catarina desde 1982, Concórdia (SC), 26 de fevereiro de 2007.

Entrevista 3. Entrevista concedida ao autor por um produtor integrado da Sadia, Francisco Beltrão (PR), 24 de maio de 2007.

Fontana, A. História da minha vida, Petrópolis, Vozes, 1980.

Fontana, Y.M. Como fritar as Josefinas. A mulher nos bastidores da empresa familiar brasileira, 5a ed., São Paulo: Cultura Editores Associados, 2000.

IPARDES. Análise da competitividade da cadeia agroindustrial de carne de frango no estado do Paraná. Curitiba: IPARDES, 2002.

Lopes, J. Análise econômica de contratos de integração usados no complexo agroindustrial avícola brasileiro, Viçosa: UFV, 1992.

Mior, L.C. Empresas agroalimentares, produção agrícola familiar e competitividade no complexo carnes de Santa Catarina, Rio de Janeiro: UFRRJ, 1992.

Perdigão. <http://www.perdigao.com.br>, várias consultas.

Pessali, H. "Teoria dos custos de transação: uma avaliação à luz de diferentes correntes do pensamento econômico", Dissertação apresentada ao Curso de Mestrado em Desenvolvimento Econômico, Curitiba, Departamento de Economia, UFPR, 1998.

"The rhetoric of Olivier Williamson's transaction cost economics", Journal of Institutional Economics, 2 (1), p.45-65, 2006. 
Revista Integração, órgão interno da Fundação Attilio Francisco Xavier Fontana, bimestral, jun., 1986 a nov./dez., 2001.

Rizzi, A. "Mudanças tecnológicas e reestruturação da indústria agroalimentar: o caso da indústria de frangos no Brasil", Tese de Doutorado, Campinas, UNICAMP, 1993.

Sadia. <http://www.sadia.com.br>, várias consultas.

Projeto 21, Concórdia: Departamento de Fomento Agropecuário, 1988.

Relatórios anuais, 1976 a 2003.

Schmidt, G.S.; Figueiredo, E.A.P.; Ledur, M.C. "Genetic gain for body weigt, feed conversion and carcass traits in selected broiler strains", Revista Brasileira de Ciência Avicola, v.8, p.29-32, 2006.

Silva, H. "A gestão do território pelo grupo Sadia no município de Concórdia, Santa Catarina”, Dissertação de Mestrado, Florianópolis, UFSC, 1991.

Silveira P.; Maria I. Produtor e agroindústria: consensos e disensos. O caso de Santa Catarina, Florianópolis: Secretaria de Estado da Cultura e do Esporte, Editora da UFSC, 1990.

Simon, H. "Organizations and markets", Journal of Economic Perspectives, v.5, n.2, p.25-44, 1991.

Sorj, B. Estado e classes sociais na agricultura brasileira, $2^{a}$ ed., Rio de Janeiro: Editora Guanabara, 1980.

Tassara, H.; Scapin, A. Perdigão, uma trajetória para o futuro, Videira: Empresa das Artes, 1996.

Teixeira, Francisco M.P. Sadia, 50 anos construindo uma história, São Paulo: Prêmio Editorial, 1994.

Williamson, O.E. Markets and hierarchies, Nova York: The Free Press, 1975. 
Williamson, O.E. "Comparative economic organization: the analysis of discrete structural alternatives“, Administrative Science Quartely, v.36, p.269-296, 1991.

Les institutions de l'économie, Paris: InterEditions, 1994. [Tradução de The economic institutions of capitalism, Nova York: The Free Press, 1985.]

. "Hierarchies, markets and power in the economy: an economic perspective", Industrial and Corporate Change, v.1, n.1, p.21-49, 1995.

"Comparative economic organization: the analysis of discrete structural alternatives”, Administrative Science Quarterly, v.36, p.269-296, 1998.

ENDEREÇOS PARA CORRESPONDENCIA:

Armando Dalla Costa - ajdcosta@ufpr.br

Rua Jeremias Maciel Perreta, 1.288 - casa 15

Curitiba - PR CEP: 81210-310

Fone (41) 9908-5861 